\title{
PEMANTAUAN DAN PENGATURAN PROXY SERVER DALAM PENGAKSESAN INTERNET DENGAN OTENTIKASI BERBASIS WEB
}

\author{
Januar Santoso; Normandito Wijaya; Khowi Siswandi \\ Jurusan Teknik Informatika, Fakultas Ilmu Komputer, Bina Nusantara University \\ Jln. K.H. Syahdan No 9, Palmerah, Jakarta Barat 11480 \\ januarsnt@binus.edu
}

\begin{abstract}
The quick expanding user of World Wide Web (WWW) has been made a development in proxy server in limited access to the users. Therefore, it needs the limit with designing and implementing proxy server configuration system and authentication in internet web-based usage so it will ease in supervising and using internet facility. The method used is analysis and web-based system design. The expected result is the easier in supervising and controlling internet facility using proxy server and reducing the leaking of internet facility usage through authentication (security).
\end{abstract}

Keywords: proxy server, authentication, web.

\begin{abstract}
ABSTRAK
Perkembangan yang sangat cepat dari pengguna World Wide Web (WWW) telah membuat perkembangan juga pada proxy server dalam memberikan batasan akses pada penggunanya. Maka dari itu perlu adanya pembatasan dengan perancangan dan implementasi sistem konfigurasi proxy server dan otentikasi penggunaan internet berbasis web sehingga mempermudah dalam pengawasan dan penggunaan fasilitas internet. Metode yang digunakan ialah analisa dan perancangan sistem berbasis web. Hasil yang ingin dicapai adalah kemudahan dalam pengawasan dan pengontrolan penggunaan fasilitas internet menggunakan proxy server dan pengurangan kebocoran penggunaan fasilitas internet melalui otentikasi (keamanan).
\end{abstract}

Kata kunci : proxy server, otentikasi, web. 


\section{PENDAHULUAN}

Perkembangan teknologi di bidang informasi telah memberikan pengaruh dalam segala aspek kehidupan. Perilaku masyarakat pun mengalami perubahan yang luar biasa. Hal itupun berkembang dengan seiringnya bertambahnya jumlah pengguna internet. Internet dapat diakses dimana dan kapan pun juga. Hal ini menjadi pemicu hal-hal yang terjadi saat ini dengan penyalahgunaan fasilitas internet. Jumlah perkembangan pengguna fasilitas internet tidak dapat kita batasin tetapi kita dapat membatasi penggunaanya di mana pun dan kapan pun kita dapat batasi.

Pada saat ini kita dapat melihat banyak sekali perusahaan dan usaha bisnis lainya menggunakan fasilitas internet untuk membantu proses bisnisnya agar tetap berjalan. Demikian juga di dalam pengelolaan tempat usaha seperti kafe sebagai sebuah tempat yang sering digunakan orangorang sebagai tempat makan dan biasa digunakan untuk menghabiskan waktu bersama kerabat.

Pada umumnya fasilitas kafe yang ada tidak lain berupa tempat dengan suasana nyaman, santai dan hiburan yang menarik. Fasilitas-fasilitas yang diberikan pada umumnya sudah terbilang cukup, akan tetapi jika dilihat dari semakin berkembangnya teknologi, kemajuan informasi dan kebutuhan akan informasi, maka kebutuhan customer masih belum terpenuhi. Pada jaman sekarang ini, customer menginginkan agar mereka dapat mengakses informasi yang cepat dan mudah. Salah satu cara mengakses informasi yang cepat dan mudah adalah melalui internet. Indonesia saat ini mulai menjamur kafe yang menyediakan fasilitas akan penggunaan akses internet yang menggunakan teknologi jaringan nirkabel ( wireless / WiFi ).

Tuntutan akan kebutuhan informasi membuat pengelola kafe menyediakan fasilitas tambahan berupa layanan akses internet yang mudah dan cepat. Pada umumnya, layanan internet yang diberikan oleh pengelola cafe adalah menggunakan jaringan wireless atau yang lebih dikenal dengan hotspot. Kendala yang ditemukan saat ini penggunaan fasilitas internet masih belum adanya pengaturan dalam penggunaan hak aksesnya. Kendala dalam pengaturan penggunaan hak akses tersebut diantarnya seperti masih belum adanya pengaturan jumlah bandwith yang dipakai, pembatasan dalam mengakses halaman-halaman web yang tidak diinginkan.

Penggunaan MikroTik yang terbilang cukup mahal merupakan salah satu kendala di beberapa kafe atau small business untuk menyediakan fasilitas internet. Harga sebuah MikroTik yang berkisar 1.7 juta -5 juta tergantung jenisnya dan termasuk harga lisensi yang harus dibayar untuk penggunaan MikroTtik merupakan suatu hal yang harus diperhitungkan kembali untuk para pengelola kafe atau small business jika ingin memasangnya. Dewasa ini banyak sekali pengelola yang menginginkan biaya yang murah dengan tidak perlunya lisensi dan aplikasi yang freeware dan juga bersifat open source.

\section{Tujuan dan Manfaat}

Tujuan dari penulisan ini berhubungan dengan adanya proyek pengembangan aplikasi yang meliputi: merancang sistem otentikasi untuk membatasi banyaknya pengguna yang bebas mengakses, Mengetahui penggunaan bandwith yang terpakai agar dapat digunakan sebagai acuan pengambilan keputusan atas kebijakan penggunaan fasilitas internet, dan merancang user interface yang sederhana untuk memudahkan pengelola fasilitas internet / network administrator.

Adapun manfaat yang diperoleh dari penulisan ini diantaranya: mempermudah dalam mengatur konfigurasi SQUID melalui user interface yang disediakan, mencegah terjadinya penyalahgunaan fasilitas internet, dan mencegah kebocoran penggunaan fasilitas internet dengan menggunakan sistem otentikasi. 


\section{Tinjauan Pustaka}

\section{Jaringan Nirkabel}

Jaringan Nirkabel (wireless) adalah suatu jaringan yang menggunakan frekuensi radio untuk komunikasi antara perangkat komputer dan akhirnya titik akses yang merupakan dasar dari komunikasi radio dua arah yang tipikalnya bekerja di bandwidth $2,4 \mathrm{GHz}(802.11 \mathrm{~b} / \mathrm{g})$ atau $5 \mathrm{GHz}$ (802.11 a). Kebanyakan peralatan mempunyai kualifikasi Wi-Fi, IEEE 802.11 b atau akomodasi IEEE $802.11 \mathrm{~g}$ dan menambahkan beberapa tingkat keamanan seperti WEP dan/atau WPA. Tulang punggung jaringan biasanya menggunakan kabel, dengan satu atau lebih titik akses jaringan menyambungkan pengguna nirkabel ke jaringan berkabel. Jaringan nirkabel memungkinkan orang melakukan komunikasi dan mengakses aplikasi dan informasi tanpa kabel.

\section{Hotspot}

Berdasarkan Gaier (2005) Hotspot adalah lokasi LAN nirkabel publik. Hotspot berada di tempat-tempat umum yang ramai dikunjungi termasuk bandara, hotel, convention center, dan kafe. Di lokasi ini terdapat wireless access point yang menghubungkan perangkat mobile (seperti laptop, dan smart phone) ke internet dengan menggunakan standar teknologi WLAN (Wi-Fi).

Berdasarkan pendapat Vladimirov et al (2004,p 550) access point adalah sebuah perangkat jaringan pada layer 2 yang menghubungkan kabel dan nirkabel dan mengontrol parameter jaringan di jaringan LAN nirkabel.

Fitur yang ditawarkan pada hotspot secara komersil dapat berupa: (1) Sebuah portal dimana user diarahkan untuk otentikasi dan pembayaran; (2) Pilihan pembayaran menggunakan kartu kredit dan lain-lain; dan (3) Mengijinkan akses situs tertentu dengan gratis (walled garden).

Meskipun demikian, banyak hotspot terbuka dan digunakan dengan gratis, baik yang dibuat oleh perusahaan pemerintah atau swasta untuk menarik perhatian pelanggan. Saat ini pun banyak universitas maupun sekolah yang telah memilki hotspot.

\section{Proxy Server}

Proxy server merupakan komponen penengah antar user agent, bertindak sebagai server dan client yang menerima request message dari user agent dan menyampaikan pada user agent lainnya.

Request yang diterima dapat dilayani sendiri atau disampaikan (forward) pada proxy lain atau server lain. Proxy server menterjemahkan dan/atau menulis ulang request message sebelum menyampaikan pada user agent tujuan atau proxy lain.

Proxy server merupakan pusat komunikasi yang dapat dicapai oleh user agent secara langsung dan juga bertugas menyimpan data hasil sesi komunikasi yang terjadi antara UAC dan UAS. (Raharja, 2004, VoIP Rakyat).

\section{Squid Cache}

Squid adalah sebuah proxy server dan web cache daemon. Squid dirancang dan dijalankan di UNIX System tetapi bisa dijalankan di Windows dengan menggunakan software Cywin yang merupakan software yang free dan dikembangkan oleh Cygnus Solutions untuk digunakan di Windows. Dengan mengunakan Squid kecepatan web server dapat dipercepat dengan adanya penyimpanan web cache, DNS dan resource dari jaringan, Squid juga berlisensi GNU General Public License.

Squid dikatakan sebagai server proxy cache yang mempunyai performansi yang tinggi dan mendukung operasional FTP, Gopher, dan HTTP. Dalam memenuhi permintaan client, Squid 
menangani dalam satu proses I/O dan tidak bersifat blocking. Squid hampir bersifat monolitik (seperti Sendmail) dimana seluruh pekerjaan mulai dari menangani permintaan client, mengambil, mencari, dan menyimpan objek serta pengaturan memori, seluruhnya itu hampir dilakukan oleh satu proses. Hampir tidak ada proses lain, kecuali untuk versi terbaru, untuk proses I/O squid menyerahkan operasionalnya pada aplikasi lain yaitu diskd.

Squid dibuat oleh sebuah komunitas internet dan dipimpin oleh Duane Wessel dari National Laboratory for Applied Network Research yang dibiayai oleh National Science Fondation. List dari kontributor dapat kita lihat di http://www.squid-cache.org/CONTRIBUTORS.

Jenis varian UNIX yang sampai saat ini diketahui talah berhasil menjalankan Squid diantaranya : Linux (semua distro), FreeBSD, NetBSD, BSDI, OSF and Digital UNIX, IRIX, SunOS/Solaris, NeXTStep, SCO UNIX, AIX, dan HP-UX.

Selain varian UNIX, ternyata squid juga bisa dijalankan di atas OS/2 dan WinNT. ( Maryanto, Dodi, 2001 , Optimasi Akses Internet dengan SQUID).

\section{MRTG}

Multi Router Traffic Grapher (MRTG) adalah aplikasi yang digunakan untuk memantau beban trafik pada link jaringan. MRTG akan membuat report dalam bentuk harian, mingguan, bulanan dan tahunan berdasarkan interface router yang ada. MRTG akan membentuk dokumen dalam bentuk HTML, MRTG itu sendiri terdiri dari script perl yang menggunakan Simple Network Management Protocol (SNMP) untuk memantau trafik pada router.

MRTG merupakan software yang berlisensi GNU General Public License. MRTG tidak hanya untuk melihat trafik jaringan, tetapi dapat juga digunakan untuk melihat trafik CPU load, memori load. Ada banyak tool seperti MRTG, seperti cacti, ntop, nagios, iptraff. Agar MRTG dapat berjalan baik dibutuhkan software penunjang lainnya antara lain SNMP, Web Server ( apache 2.0 ).

\section{WPA}

Singkatan Wi-Fi Protected Access, standar Wi-Fi untuk meningkatkan fitur keamanan WEP. Teknologi ini di desain untuk bekerja pada produk Wi-Fi eksisting yang telah memiliki WEP (semacam software upgrade ). Teknologi WPA menawarkan dua macam peningkatan kemampuan WEP :

1. Meningkatkan enkripsi data dengan teknik Temporal Key Integrity Protocol (TKIP). TKIP mengacak kata kunci menggunakan algoritma hashing dan menambah Integrity Checking Feature, untuk memastikan kunci belum pernah digunakan secara tidak sah.

2. Otentikasi user, yang tidak tersedia di WEP. Melalui Extensible Authentication Protocol (EAP) maka wireless client harus melakukan otentikasi terlebih dahulu sebelum memasuki jaringan. WEP dapat membatasi akses ke jaringan berdasarkan MAC address yang spesifik untuk setiap perangkat. Tapi MAC address adalah sebuah kode yang mudah dideteksi melalui akses tidak sah dan dapat dengan mudah dipalsukan atau digandakan. EAP memberikan solusi yang lebih aman dengan menerapkan Public Key Encryption System untuk memastikan hanya pengguna sah dapat memasuki jaringan. 


\section{METODE}

PT Sistem integral Perkasa ( SiP ) merupakan suatu perusahaan yang bergerak dalam bidang distribusi alat-alat jaringan, dimana berencana selain menjual alat perusahaan bermaksud menyediakan jasa pemasangan hotspot. Kendala juga ditemukan yaitu hotspot yang dibangun belum mempunyai fasilitas pengaturan jaringan jika hanya menggunakan peralatan berupa Modem ADSL dan sebuah Wireless LAN atau sebuah Access Point , sehingga belum adanya konfigurasi jaringan karena tidak adanya router. Jika ingin mengkonfigurasikan jaringan, maka perlu ditambah lagi sebuah router yang memerlukan teknisi jaringan untuk mengkonfigurasi router tersebut, sehingga akan terjadi pemborosan dalam biaya operasional dan pemeliharaan. Perlunya bantuan teknisi dikarenakan sulitnya instalasi dan konfigurasi proxy server.

Dikarenakan permasalahan diatas maka penulis mencoba untuk memberikan solusi berupa rancangan perangkat keras yang akan digunakan, sistem yang akan dijalankan, rancangan sistem berupa struktur menu dan State Transtition Diagram (STD) serta rancangan layar user interface yang akan dibuat.

\section{Rancangan Perangkat Keras}

Untuk membangun suatu jaringan awal, peralatan atau device yang dibutuhkan meliputi :

- 1 unit CPU yang digunakan sebagai proxy server Squid, web server, dan PC Router.

- Modem ADSL jika belum terdapat fasilitas internet.

- 1 buah Wireless LAN yang dapat dijadikan sebagai Access Point maupun Repeater.

- Kabel UTP untuk menghubungkan Modem ADSL - PC Server - Access Point.

Dalam implementasinya client dapat menggunakan laptop/notebook yang dapat menggunakan koneksi wireless atau komputer desktop yang terhubung dengan Wireless LAN.

\section{Kebutuhan Hardware untuk CPU Server}

Kebutuhan hardware untuk Squid memang besar. Untuk menghasilkan troughput yang maksimal diperlukan komponen hardware yang cukup besar. Kebutuhan ini berbanding lurus dengan beban, beberapa komponen harus dibutuhkan untuk membuat sebuah PC sebagai proxy server diantaranya :

1. Prosessor

Squid tidak memerlukan sebuah prosessor yang cepat. Untuk beban 1000 permintaan / menit, Squid sudah berjalan dengan baik pada jenis Pentium II 500. Untuk permintaan jauh dibawah itu, kebutuhan prosessor bisa di level Pentium 166.

2. Memori

Memori adalah kebutuhan pokok dari Squid. Semakin besar kapasitas harddisk yang dipilih, maka memori juga bertambah kebutuhannya. Setiap objek yang disimpan dalam harddisk, mempunyai metadata yang sebagian darinya akan tertinggal dalam memori, bernilai 72 byte. Dalam hitungan di bawah dipakai kapasitas rata-rata 1 objek sebesar 9 Kb. Angka ini didapatkan dari cachemgr.cgi

$$
\begin{aligned}
& \text { Kapasitas harddisk untuk keperluan cache } \\
& \text { Jumlah Objek = ----------------------------- } \\
& \text { Kapasitas rata-rata } 1 \text { Objek }(9 \mathrm{~Kb})
\end{aligned}
$$

1. Kapasitas Penyimpanan

Kapasitas harddisk yang digunakan tergantung dengan rumus perhitungan di atas, tergantung dari berapa besar memori yang kita punya baru kita dapat menentukan berapa besar kapsitas harddisk. 


\section{Kebutuhan Software untuk CPU Server}

Kebutuhan software juga merupakan faktor terpenting berjalan atau tidaknya aplikasi konfigurasi Squid ini. Berikut kebutuhan software yang dibutuhkan untuk menunjang aplikasi web yang akan nantinya ditanam, diantaranya :

1. OS Linux Red Hat 9.

2. SQUID 2.6 STABLE 16.

3. Apache.HTTP Server versi 2.2.6.

4. PHP 5.2.5.

5. MRTG2 versi 15.2

\section{Perancangan User Interface}

Aplikasi web ini merupakan tampilan antarmuka yang ditujukan untuk administrasi Squid server. Hal ini memberikan kemudahan administrasi dan pengaturan dalam men-setting konfigurasi file "squid.conf". Detail perancangan dari user interface web yang akan digunakan diantaranya :

- Perancangan Modul Aplikasi.

- Perancangan Struktur Menu.

Modul Aplikasi

\section{Network Configuration}

Network Configuration berfungsi sebagai modul untuk mengeset nilai HTTP Port, ICP Port yang akan digunakan oleh user, men-set nilai alamat untuk paket UDP yang masuk dan keluar dari squid, pengaturan untuk me-non-aktifkan query ICMP dan tes Reachability. Selain itu juga pengaturan untuk menghubungkan server dengan proxy server lainnya.

\section{Cache Memory and Disk Configuration}

Cache Memory digunakan untuk menyimpan sejumlah objek yang dapat disimpan dalam memori cache. Objek yang disimpan ada 2 yakni transit objek dan hot objek. Dimana transit objek adalah objek yang dalam masa transisi antara waktu cache men-download objek disampaikan kepada client. Sedangkan hot objek merupakan objek yang sering diakses - negative-cached-object URL yang ternyata tidak menghasilkan objek. Selain itu pengaturan memori cache, user admin dapat mengatur penggunaan disk untuk menyimpan cache dalam harddisk termasuk batas minimum dan maksimum suatu objek disimpan dalam harddisk. Serta pengaturan kapan objek tersebut akan dihapus dari harddisk.

\section{DNS Configuration}

DNS atau kepanjangan dari Domain Name System (atau Service/Server), adalah layanan dalam internet yang berfungsi menerjemahkan nama domain tertentu ke dalam format numerik Internet Protocol (IP) address, misalnya nama domain www.example.com akan diterjemahkan ke dalam IP address 198.105.232.4. Nama domain terdiri atas deretan alfabetis sehingga mudah diingat. Namun, sesungguhnya internet bersandar pada prinsip numerik IP address tersebut.

DNS bekerja dalam modus client-server. Artinya adalah komputer client mencari nama domain atau IP address, kemudian server yang akan memberikan informasi di mana lokasi nama domain atau IP address tersebut bisa diakses. Pada browser, apabila kita mencari sebuah nama domain, misalnya binusmaya.binus.ac.id, maka browser akan melihat file resolv.conf untuk mencari name server dari domain yang dimaksud. Pada modul konfigurasi ini user admin dapat melakukan penge-set-an alamat DNS yang ada. Serta waktu timeout jika DNS tidak memberikan sinyal jawaban pada client.

\section{Restrict Site}

Restrict site berfungsi sebagai modul yang memblok akses terhadap website tertentu. Restrict site membantu dalam pem-filter-an website yang dianggap terlarang. Terdapat beberapa metode yang dapat digunakan untuk memblok sebuah website yaitu :

- Memblok website berdasarkan domain name, yang dimaksudkan adalah memblok semua website yang berasal dari satu domain name. 
- Memblok website berdasarkan sebagian kata yang ada pada URL-nya.

- Memblok website berdasarkan IP dari website tersebut.

\section{Restrict IP}

Restrict IP berfungsi sebagai modul yang membatasi IP tertentu mengakses sebuah internet. Hal ini berguna jika disuatu instansi menginginkan salah satu karyawannya tidak dapat mengakses internet tetapi masih dapat menggunakan Local Area Network (LAN).

\section{Monitoring}

Network monitoring adalah sebuah bentuk sistem yang secara konstan me-monitor kegiatan jaringan komputer. Monitoring yang dimaksud di sini lebih banyak tentang monitoring besarnya bandwith dari user dengan menanamkan aplikasi MRTG.

\section{Administrative Configuration}

Administrative disini bertujuan untuk memberitahukan kepada client jika mengalami masalah pada cache di squid. Selain itu juga mengatur akan kepemilikan objek yang digunakan atas nama user dan group yang menggunakannya.

\section{Reset/restart}

Reset adalah modul yang digunakan untuk mengembalikan konfigurasi squid pada kondisi asli atau setting-an default.

Restart digunakan untuk me-restart kembali proxy squid dari hasil reconfigure file "squid.conf".

\section{Perancangan Struktur Menu}

Rancangan struktur menu dari aplikasi terdapat pada Gambar 1.

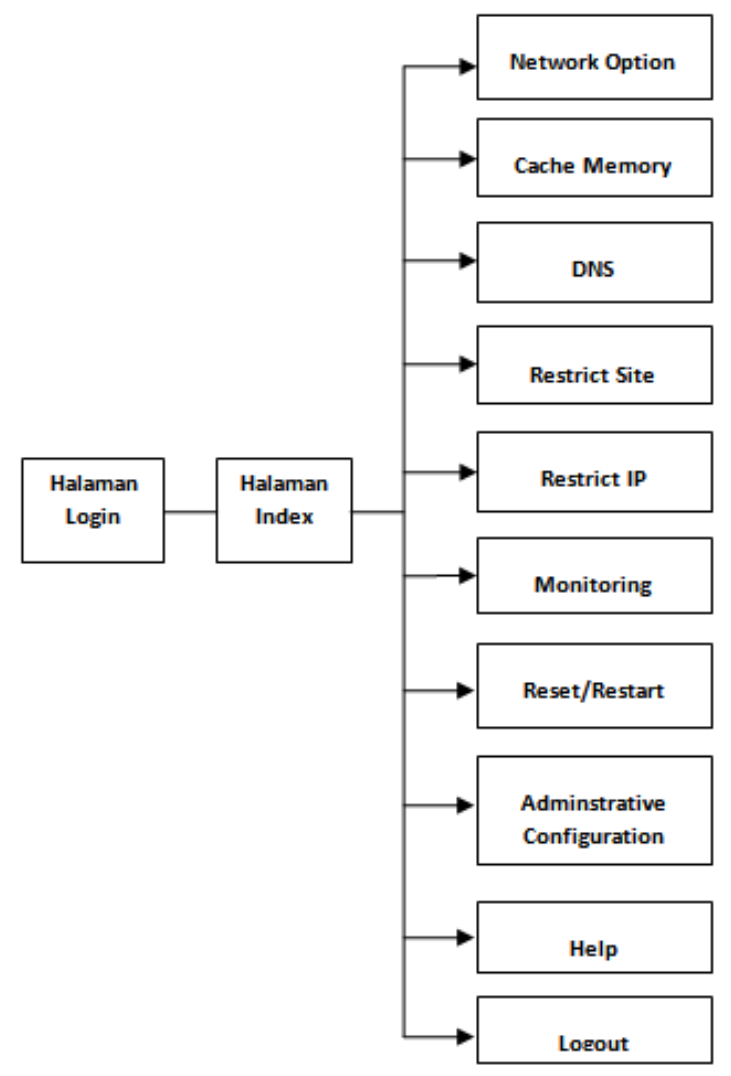

Gambar 1 Struktur Menu 


\section{HASIL DAN PEMBAHASAN}

Perangkat keras yang digunakan adalah berupa access point dan sebuah $P C$ yang digunakan sebagai PC. Perangkat lunak yang digunakan dalam sistem ini adalah: (1) Sistem operasi Linux Red Hat versi 9, (2) Proxy server yaitu Squid-2.6 STABLE 16; (3) Web server yaitu Apache.HTTP Server versi 2.2.6, PHP 5.2.5; dan (4) Monitoring yaitu MRTG versi 2.15.2.

\section{Prosedur Instalasi Sistem}

Prosedur instalasi yang dilakukan ialah pertama kali instalasi OS -nya telebih dahulu (Red Hat) dengan tipe instalasi sebagai server. Pada saat instalasi Red Hat jangan lupa untuk memilih option pada package dhcp, dhcp-level, net-snmp, net-snmp-devel, dan net-snmp-utils. Kedua lakukan instalasi sistem dengan login sebagai "root" lalu instal Proxy Server Squid, MRTG dan aplikasi webnya dimana peneliti sudah menyiapkan sebuah file yang hanya dijalankan 1 kali saja untuk ditanamkan pada PC Server tersebut.

\section{Prosedur Instalasi Sistem}

Aplikasi siap dipakai dan terbagi menjadi 2 yakni aplikasi untuk admin dan aplikasi untuk end user. Dimana aplikasi untuk admin memuat tentang halaman-halaman konfigurasi dalam pengaksesan jaringan internet yang melalui proxy server tersebut. Aplikasi untuk end user hanya digunakan untuk mencata $\log$ aktifitas yang dilakukan oleh user, user diwajibkan untuk login terlebih dahulu.

\section{Pengujian Sistem}

Sistem dapat diimplementasikan pada jaringan LAN maupun jaringan wireless. Penulis melakukan pengujian sistem melalui jaringan LAN dengan menggunakan laptop sebagai PC router maupun sebagai server.

\section{Skema Pengujian Sistem}

Pengujian dilakukan dengan menggunakan: (1) 1 buah laptop sebagai PC router dan server; (2) 1 buah switch; dan (3) 10 buah PC yang terhubung pada switch sebagai LAN. Skema pengujian sistem ditampilkan pada Gambar 2.

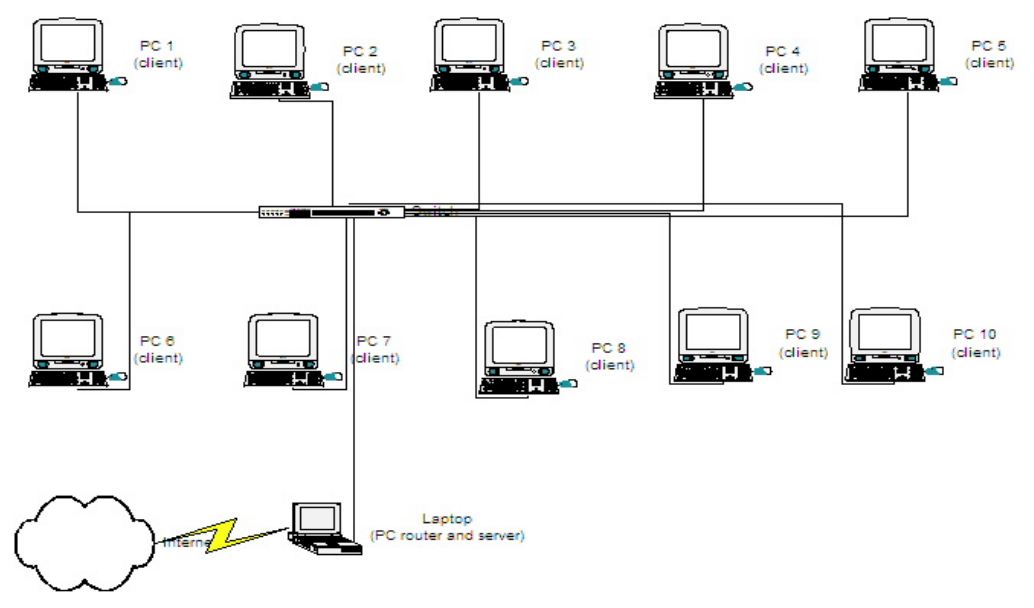

Gambar 2 Skema Pengujian 


\section{Evaluasi}

Setelah dilakukan pengujian melalui 10 PC mengakses internet secara bersamaan, proxy server berjalan dengan baik dan cepat. Selain itu bandwith yang digunakan menjadi lebih kecil jika 10 $P C$ mengkases halaman yang sama, hal ini dikarenakan cache menyimpan objek dari halaman yang sudah pernah diakses sehingga cukup 1 kali men-download objek dari halaman tersebut.

Untuk pertama kali mengakses halaman web memerlukan waktu cukup lama karena harus menyimpan objek ke dalam cache memori.

\section{PENUTUP}

\section{Simpulan}

Kesimpulan yang didapat dari evaluasi sistem web ini adalah: (1) Penggunaan user interface berbasiskan web mempermudah administrator untuk mengatur penggunaan hak akses internet; (2) Instalasi penanaman sistem proxy server yang mendukung sistem web ini sudah dipermudah dengan file instalasi yang diberikan; dan (3) Penggunaan sistem pengaturan, pemantauan dan otentikasi berbasiskan web sudah praktis dan efisien karena user tidak perlu lagi secara langsung mengubah sistem proxy server yang ada.

\section{Saran}

Saran yang didapat dari hasil evaluasi sistem web ini adalah: (1) Pengembangan fitur-fitur pengaturan penggunaan internet lainnya; (2) Penambahan fitur-fitur pengaturan bandwidth jaringan; (3) Pengembangan terhadap sistem untuk memberikan pelayanan dalam skala yang jahu lebih besar, misalkan jumlah pengguna atau user lebih dari 255, karena yang ada pada saat ini dibatasi untuk 100 pengguna; dan (4) Penerapan billing system pada sistem ini.

\section{DAFTAR PUSTAKA}

Smith, L. D., Case, T. L. (1995). Managing Local Area Networks. New York: McGraw-Hill.

Fisher, C. (2000). Redhat Linux Administration Tools. New York: McGraw-Hill.

Lusignan, R.., Steudler, O., \& Allison, J. (2000). Managing Cisco Network Security, Syngress.

Maiwald, E. (2004). Fundamentals of Network Security. McGraw-Hill Technology Education.

Maryanto, D. (2001). Buku Pintar Internet Optimasi Akses Internet dengan Squid. Jakarta: Elex Media Komputindo.

Vacca, J. R.. (2002). Wireless Data Demystified . McGraw-Hill Networking.

Subramanian, M. (2000). Network Management : Principles and Practise. Addison-Wesley.

Wessels, D. (2004). Squid: The Definitive Guide. O'Reilly 